\title{
A quantitative thermographic investigation of cooling of power electronic sources by forced convection cold plates
}

\author{
by G. Cesini, V. Moro, R. Ricci
}

Dipartimento di Energetica, Università di Ancona, via Brecce Bianche, 60100 Ancona, Italy

\begin{abstract}
Aim of this work is the utilization of thermographic methods to analyse quantitatively the thermal behaviour of a rectangular channel cold-plate cooled by a forced flow of air. The infrared thermography is used to measure the case temperature of the electronic components in order to evaluate the local total thermal resistance of the component-cold plate system and the temperature increase on the unpowered components caused by powered components placed near-by (thermal mutual effects between the components). A method based on the superposition principle is also proposed to calculate the mutual thermal effects between the components.
\end{abstract}

\section{NOMENCLATURE}

\begin{tabular}{|c|c|c|c|c|}
\hline $\begin{array}{l}R_{\text {tot }} \\
P \\
T_{c}\end{array}$ & $\begin{array}{l}\text { Total Thermal Resistance } \\
\text { Heat power } \quad \text { W] } \\
\text { Case temperature }\left[{ }^{\circ} \mathrm{Cl}\right.\end{array}$ & {$[\mathrm{KM}]$} & $\begin{array}{l}T_{8 d} \\
T_{\text {air }} \\
\vartheta(i, j)\end{array}$ & $\begin{array}{l}\text { Adiabatic temperature }\left[{ }^{\circ} \mathrm{C}\right] \\
\text { Inlet air temperature }\left[{ }^{\circ} \mathrm{C}\right] \\
\text { Dimensionless adiabatic temperature }\end{array}$ \\
\hline
\end{tabular}

1. Introduction

The thermal control of power electronic devices and components is a very important area of research; the specific thermal fluxes involved by these elements is ranging from $\mathbf{4 0}$ to $\mathbf{7 0}$ $W / \mathrm{cm}^{2}$ so very efficient cooling system is required to ensure proper operating junction temperature of the components.

Extruded heat sinks are normally used in standard electronic applications but owing to the limits of the extrusion technology it is impossible to realize heat transfer areas with very large fins density; brazed cold plate heat sinks seem to be better in order to overcome these limits.

Especially in television broadcasting the cooling systems based on the cold plates could solve the thermal problems caused by MOS linear power transistors used in VHF and UHF transmitters and transposers.

In these applications, as in other power devices, the thermal sources are non uniformly distributed on the heat sink so it is very important to evaluate the local thermal resistance of the system in order to establish the criteria for the components assembling; at the same time is also important to determine the thermal influence between the electronic components during the work.

As matter of fact the thermal performances of the heat sink are normally evaluated using uniform heat flux or uniform constant temperature boundary conditions so that the thermal resistance values are not applicable to the case of cold plates for electronic power applications with distributed heat sources.

A more detailed thermal analysis of the system involves an evaluation of the components case temperature for single powered condition to study the dependence of the thermal resistance on the cold plate components position; in order to determine the thermal influence between the components it is also necessary a thermal mapping of the system when more than one component is electrically supplied simultaneausly.

For these applications the infrared thermography may be a very effective method to measure at the same time the temperature distribution on the components-cold plate system, especially for the non intrusive aspect of the tecnique. Moreover only a little amount 
of thermographic observations is requested to define the local thermal resistance and the mutual influence between the components. While several studies of the mutual influence effects between different heated sources are reported in literature for the direct contact forced air cooling of electronic components placed in channels [1,2], only a few papers are concerning the study of finned heat sinks operating in forced convection with localized heat fluxes boundary conditions, $[3,4]$. So that the correlations obtained for finned compact exchangers [5] are normally used to design cold plate heat sinks.

This work aims at studying the quantitative application of IR thermography to determine the thermofluidynamic performances of a tin brazed rectangular channeled cold plate, forced air cooled, which is used for the thermal control of a power transmitter for broadcasting television [6].

\section{Experimental Apparatus}

The experimental set-up consists of a small wind tunnel to perform controlled fluid dynamic conditions at inlet. The cold plate is $150 \mathrm{~mm}$. long and $500 \mathrm{~mm}$. wide on the plan, inside shows 200 rectangular channels, $2 \mathrm{~mm}$. wide and $40 \mathrm{~mm}$. high. It is made in aluminium with copper cladding.

Nine power electronic resistors are placed on the extemal surface of the cold plate to realize localized heat fluxes boundary conditions (figure1). The resistors can be separately fed by a multiple outputs feeder either one by one or simultaneously.

The air flow rate is evaluated by a Pitot Static Tube inserted in a suction circular duct; many radial profiles of the velocity are measured to find a relation between the central position velocity and mean velocity [7] and the probe errors are evaluated by using standard correlations [8].

The monitoring system allows to measure the pressure losses through the cold plate and the thermal distribution on the components plan; three thermographic apparatus have been used during the research: an AGA-870 SW, an AGA-880 LW and, finally, a Thermovision 900 System based on LW detector.

\section{Results}

The experimental pressure losses through the cold plate have been compared with the correlations existing in literature $[6,9]$ for a rectangular channels assembly. The comparison shows a very good agreement between the data $[7,10]$.

The thermal analysis of the cold plate has been divided in two different steps:

- a comparison between the thermal resistance of the system for one-by-one powered

resistors boundary condition and for uniform heat flux boundary condition

- a study of the components mutual thermal influence performed by using the technique of the effects superposition.

The first step of analysis, concerning the case of one-by-one powered resistors, reported in [10], shows a little dependence of the component total thermal resistance on the air flow rate and heat power values. This behaviour is connected with the thermal self-adjustment phenomenon of the components itself: as a matter of fact, at low flow rates, when the values of the convective heat transfer coefficient in the channels are smaller, the conductive diffusion on the surface of the cold plate plays a significant role, so that a wider area is working to dissipate the heat load.

When the flow rate rises, the system thermal behaviour shows a conductive diffusion on a reduced area but the cold plate works at higher values of the convective coefficient. The combined counteracting effects of the two phenomena help to keep total thermal resistance constant.

The total thermal resistance of the cold plate-system component is defined as

$$
R_{t o t}(i)=\frac{T_{c}(i)-T_{a i r}}{P(i)}
$$


The second step of the thermal analysis is concemed on the evaluation of the thermal influence between the components; in fact, when a single component is supplied, the case temperature of the near-by components is also increased owing to the thermal diffusion effects. The value of the temperature increase depends on the number and position of the supplied components. The temperature achieved by a component when its power is switched off is defined the adiabatic temperature of the component $[1,11]$ that in dimensionless formulation is:

$$
\vartheta(i, j)=\frac{T_{a d}(j)-T_{a i r}}{T c(i)-T_{a i r}}=\frac{T_{a d}(j)-T_{a i r}}{R_{\text {tot }}(i) \cdot P(i)}
$$

where $j$-index is referred to the unpowered component and $i$-index to the powered one; so $T_{2 d}(j)$ is the temperature achieved by the $j$-th unpowered when only the $i$-th component is switched on.

When many components are assembled on the cold plate surfaces is difficult to evaluate the dependence of the mutual thermal effects on the different parameters occuring in the problem and many experimental investigations are required to define a correlation between them.

A parameters reduction may be possible by applying the principle of effects superposition. In fact the temperature increase on a component switched-off, induced by the powered components placed near-by, could be evaluated as the sum of the increases caused by supplying one-by-one the powered components.

In this case the adiabatic temperature of the component may be write as:

$$
T_{a d}(j)-T_{a i r}=\sum_{i=1}^{n} \vartheta(i, j) \cdot R_{t o t}(i) \cdot P(i) \quad \text { for } i \neq j
$$

where $9(\mathrm{i}, \mathrm{j})$ and $R_{t a}(i)$ may be measured by infrared thermography.

Many experimental tests have been conducted on the adiabatic temperature of the components for one-by-one heating condition; in this manner $\mathbf{S}(\mathrm{i}, \mathrm{j})$ and $\mathbf{R}_{\mathrm{to}}(\mathrm{i})$ for the nine resistors have been determined.

As an example figure 2 shows the dimensionless adiabatic temperature, $\vartheta(i, j)$, of the component R6 measured by IR thermography when the components R1, R2 and R3 are feeded one-by-one by a power of $80 \mathrm{~W}$ per component. The figure shows a decrease of $\vartheta(i, j)$ when the air flow rate increases because of the reduction of the mutual influence due to the thermal self-adjustment of the heated component.

Successively for more-than-one heated component condition the adiabatic temperature of the components have been measured. Finally in order to verify the validity of the effects of superposition, when applied at this case, the adiabatic temperatures obtained with this heating condition has been compared with the values achieved by superimposing the results for the one-by-one heating conditions.

The comparisons are reported in terms of the percentage change of the adiabatic temperature, defined as:

$$
\% \text { change }=100 \cdot \frac{\left(T_{a d}(j)-T_{a i r}\right)_{\exp }-\sum_{i=1}^{n} \vartheta(i, j) \cdot R_{t o t}(i) \cdot P(i)}{\left(T_{a d}(j)-T_{a i r}\right)_{\exp }} \text { for } i \neq j
$$

Figure 3 shows the percentage error on R6 for different combinations of heating; the results, reported for the case of heating equal to $80 \mathrm{~W}$ per component, show an error ranging from $-5 \pm 15 \%$. Similar results have been obtained for larger thermal powers.

A different behaviour has been observed for a power supply of less than $50 \mathrm{~W}$ per component, figure 4 . Due to the small adiabatic temperature values, the errors involved with thermographc measurements are much higher than in the previous case, especially at high air flow rates. 


\section{Conclusions}

The thermal performance evaluation of cold plate heat sinks is very difficult in the case of localized heat sources because of the mutual influence effects between the different components.

A new characterization method is proposed which is based on the measure of the adiabatic temperature of each component by quantitative IR thermography and on the technique of the effects of superposition.

The experimental results show the applicability of this technique thanks to the weak dependence of the local thermal resistance on the air flow rate and the component power supply.

Furthermore the obtained results show that experimental errors less than $15 \%$ occur by using the new characterization method in the case of power supply values usually utilized in power electronic devices.

For lower values of the electrical power the errors are strongly higher.

\section{Acknowledgments}

This work has been carried out with the contribution of CNR, concerning the special project: Metodi Avanzati per il controllo termico dei dispositivi elettronici di potenza: raffreddamento mediante cold-plate in convezione forzata (fund CB CNR 95.00082.CTO7) and with the contribution of M.U.R.S.T. $40 \%$ fund Termofluidodinamica monofase $e$ bifase nei condotti e nelle cavita.

\section{REFERENCES}

[1] MOFFAT (R.J.), ORTEGA (A.) - Direct air cooling of electronic components, ch.3 in Advances in Thermal Modeling of Electronic Components and Systems Vol.1, Bar Cohen and Kraus eds, Hemisphere Publishing Corporation, 1988, pp. 129-282.

[2] LASANCE (C.J.M.) - Thermal management of air cooled electronic systems: new challenges for research, Thermal management of electronic systems, Kluwer Academic Publishers, 1993, pp. 3-24.

[3] FUJI (M.), SESHIMO (Y.), UENO (S.) and YAMANAKA (G.) - Forced air heat sink new enhanced fins, Heat Transfer: Japanese Research, 18, n.6, 1989, pp.53-65.

[4] BOESMANS (B.), CHRISTIAENS (F.), BERGHMANS (J.), BEYNE (E.) - Design of an optimal heat sink geometry for forced convection air cooling of Multi-Chip Modules, Thermal management of electronic systems, Kluwer Academic Publishers, Dordrecht, 1993, pp. 267 276.

[5] KAYS (W.M.) and LONDON (A. L.) - Compact Heat Exchangers, Mc Graw Hill Book Company, New York, 1984, pp. 192-204.

[6] ITELCO SpA - UHF medium power solid state transmitters and transposers ' $X$ ' series, Sheet n.1181950003, Orvieto, (Italy), 1995.

[7] CESINI (G.), FUMI (E.), MORO (V.), RICCl (R.) - Cold Plates ad aria per il raffreddamento di componenti elettronici di potenza localizzati, Proc. XIII Congr. Naz. sulla Trasmissione del Calore U.I.T, Bologna, (Italy), 1995, p.109-118.

[8] BENEDICT (R.P.), Fundamentals of temperature, pressure and flow measurements, John Wiley \& Sons, New York, 1976, pp. 339-374.

[9] KAKAC (S.), SHAH (R.K.), AUNG (W.), Handbook of single-phase convective heat transfer, John Wiley \& Sons, New York, 1987, p. 3.35. 
[10] CESINI (G.), FUMI (E.), MORO (V.), RICCI (R.) - Thermal control of broadcast transmitters by air cooled cold-plates, EUROTHERM Seminar No. 45, Leuven (Belgium), 1995, pp. 42.1-42.9.

[11] ARZIVU (D.), MOFFAT (R.) - The use of superposition in calculating cooling requirements for circuit board mounted electronic components, 32th Proc. Electr. Comp. Conf., 1982, pp.133-144.
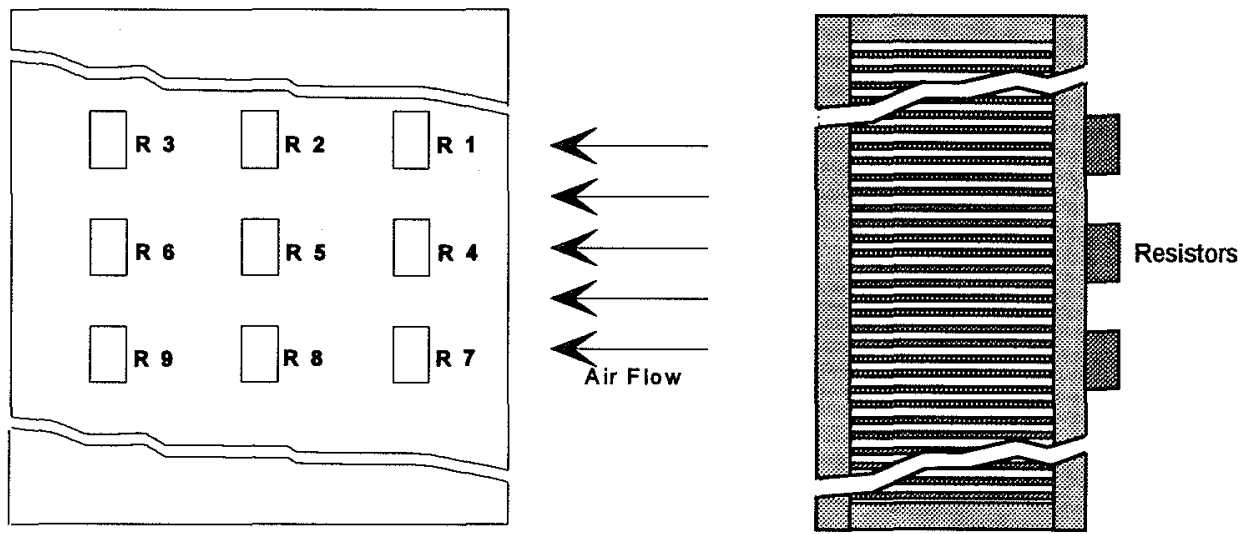

Fig. 1. Cold Plate-electronic components assembling

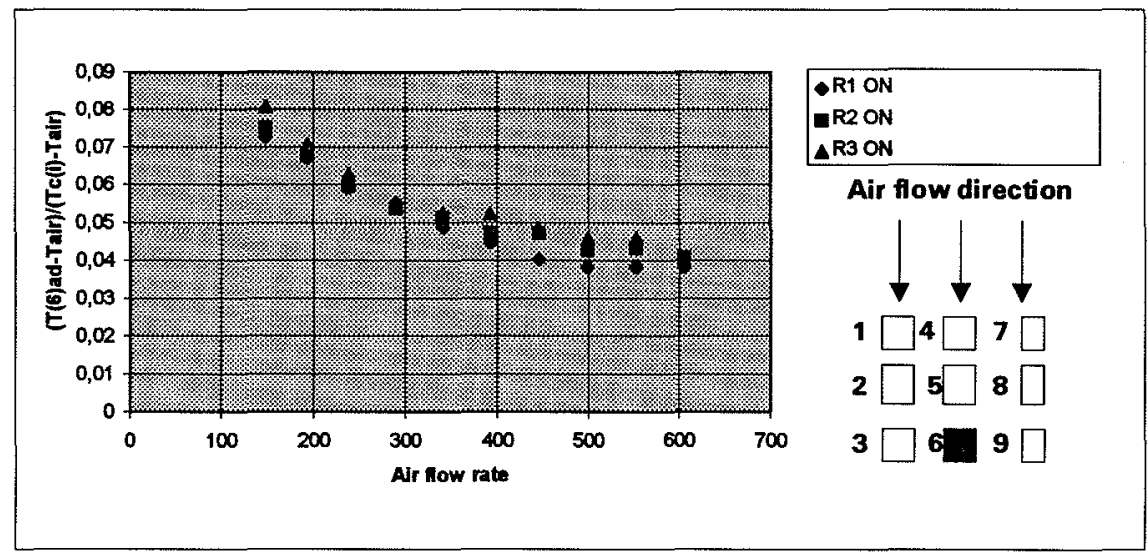

Fig. 2. Typical behaviour of $\vartheta(i, j)$ versus air flow rate 


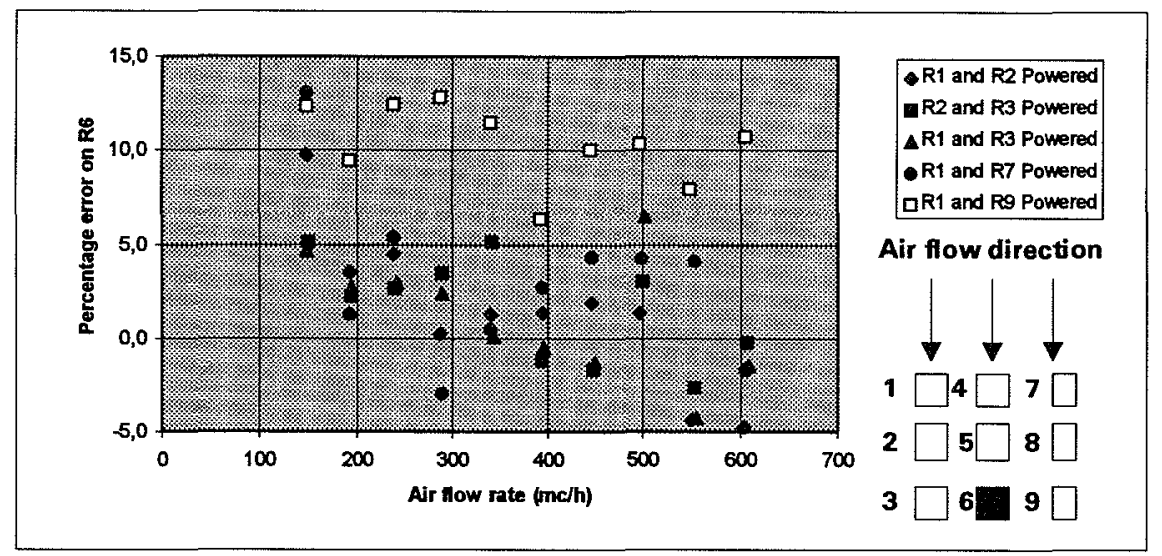

Fig. 3. Percentage error of the adiabatic temperature of R6 for a power supply of $80 \mathrm{~W}$ per component

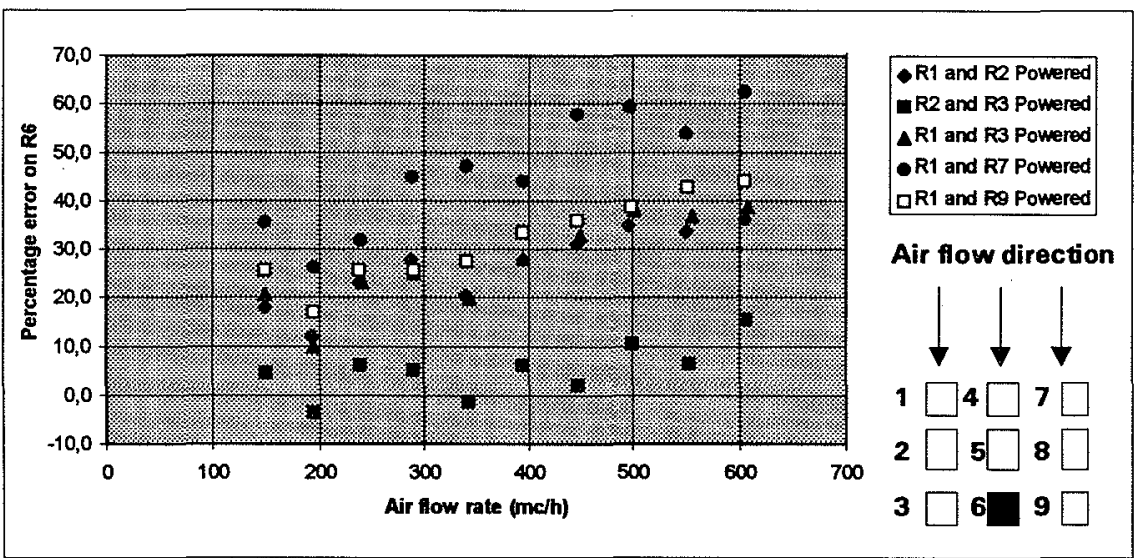

Fig. 4. Percentage error of the adiabatic temperature of R6 for a power supply of $50 \mathrm{~W}$ per component 